(p. 23) -, sale ileso por su lealtad para con ambos. Es el árbitro justo, aceptable a cada bando. Por su integridad ejemplar se salva la honra tanto de los zamoranos como de los castellanos; la guerra termina felizmente.

En resumen, la Comedia de la muerte del rey don Sancho y los demás dramas históricos de Cueva introducen en el teatro humanista para leer, temas populares ya integrados en los diálogos y tratados renacentistas. Por esta insistencia nueva en lo folklórico se desvía el teatro aristocrático hacia las formas populares -farsas y autos- comprendidas por aquella época en el Códice de autos viejos. La convergencia de las dos tendencias - la clásica y la popular- produce en la obra de Juan de la Cueva un drama perfectamente integral y representativo del pleno Renacimiento español. Ser popular en España es ser nacional; por esto Cueva no pudo menos de incorporar en su drama humanista problemas estéticos, éticos y legales heredados de la Edad Media. De resultas de esta fusión, peculiar al genio de Juan de la Cueva, nació el drama histórico de Lope y de Guillén de Castro.

The Johns Hopkins University.

BRUCE W. WARDROPPER

\title{
LOS FRANCISCO DE CASTRO DEL SIGLO XVII
}

La existencia en el siglo xvn de varios escritores llamados Francisco de Castro ha dado lugar a cierta confusión que creo debe aclararse. Por ejemplo, Cejador atribuyó a Francisco de Castro, madrileño, las tres partes de la Alegria cómica (Zaragoza, 1702), el Libro nuevo de entremeses intitulado Cómico festejo (ed. póstuma, Madrid, 1742) y las Metamorfosis a lo moderno (Florencia, 1641) ${ }^{1}$. Homero Serís dice que Francisco de Castro fue autor de El Garañón, de los Tercetos contra la vida de palacio y de las Metamorfosis a lo moderno, dando a entender, quizá sin querer, que los autores de estas obras fueron una misma persona². Mi propósito es mostrar que se trata de tres autores distintos e identificarlos, sobre todo al autor de las Metamorfosis, libro ameno del cual preparo actualmente una edición moderna.

El primero de estos autores homónimos (aunque no el primero cronológicamente) fue, como dice Cejador, entremesista madrileño. Floreció a fines del siglo xvn y durante los primeros diez años del siguiente. Compuso unas cincuenta y cinco piezas, publicadas en su mayoría en la Alegria cómica. Doce (entre ellas El Garañón) ${ }^{3}$ aparecieron en el Cómico festejo. Además, hay varias publicadas en colecciones de otros, y algunas quedan manuscritas. Según los datos biográficos que ofrece Cotarelo y Mori, fue hijo de Matías de Castro, célebre gracioso, y de Juana Gutiérrez. Empezó a trabajar antes de 1692, se casó por segunda

${ }^{2}$ Julio Cejador y Frauca, Hist. de la leng. y lit. cast., Madrid, 1916, t. 5, p. 173.

2 Homero Serís, "Guía para nuevas investigaciones", en Estudios hispanicos: Homenaje a Archer M. Huntington, Wellesley, Mass., 1952, pp. 551-552.

${ }^{3}$ Debemos apuntar que la fecha del primer manuscrito de El Garañón que da Honorio Cortís en RFE, 22 (1935), 50-51, y que repite en su artículo el profesor Seris, es errónea. Debe ser 1695 y no 1595 . El segundo manuscrito data de 1708 , como dicen ellos. 
vez en 1 7oo y murió el 2 de octubre de $1713^{ \pm}$. Así, parece imposible que escribiera las Metamorfosis, que se publicaron setenta y dos años antes de su muerte.

El segundo autor de este nombre fue Francisco de Castro y Belvis, valenciano. Hermano menor del famoso Guillén de Castro, nació el 12 de diciembre de 1572. Fue miembro de la Academia de los Nocturnos de Valencia, donde leyó los Tercetos contra la vida de palacio y una glosa al verso "El mayor mal por la mayor belleza". También escribió los sonetos "Vistió Jesús de pobre el primer manto" y "Avéysnos, fray Vincente, combidado". Ingresó en el convento de predicadores de Valencia antes de cumplir los veinte años y llegó a ser elegido prior en 1620. Murió el 6 de marzo de $1629^{5}$. Ya que no hay nada que indique que jamás viajara a Italia, tampoco pudo ser autor de las Metamorfosis, pues éste, según veremos en seguida, vivió y escribió en Italia.

En cuanto al libro titulado Metamorfosis a lo moderno (del cual existe ejemplar rarísimo, si no único, en la biblioteca de la Hispanic Society of America, en Nueva York), ofrece unos pocos indicios acerca del Francisco de Castro que lo escribió. En la dedicatoria a Pedro Médicis ${ }^{6}$ se califica de servidor de la casa de éste y dice que compuso sus versos "en lenguaje español, nacidos en Italia, digo, en Florencia, porque en Florencia está cifrada toda la hermosura de Italia". Una nota del impresor a los lectores nos informa que "el autor desta obra, compuesta más para hurtar (como se suele dezir) el ánimo a sus trauajos, que para que se imprimiesse, no es castellano, pero si hallaren en ella algunas faltas: de ortografía, sean corregidas con blandura y no críticamente". La nación del autor queda patente cuando se leen las poesías cortas contenidas al fin del libro. Además de los setenta epigramas que tratan temas mitológicos ovidianos y que dan nombre al libro, hay una "Canción del chaos y quatro edades del mundo" (en 240 versos), dieciséis motes y tres sonetos. Sólo dos de los motes están escritos en castellano; los demás, y uno de los sonetos, están en portugués. Así, el autor habrá sido de raza lusitana, residente en Florencia y adherente a uno de los Medici de menor importancia. Más precisamente, creo que fue hijo de Estevão Rodrigues de Castro. Este último, nacido en Lisboa en 1559, emigró a Italia, donde fue catedrático en la Universidad de Pisa y protomédico del gran duque de Florencia. Murió en $1697^{\top}$. En cuanto a la causa de su expatriación, sabemos que "era havido por judeu, e como tal é provavel que na emigração buscasse refugio contra as perseguições do Sancto Officio" 8 . Entre las obras suyas que reseña Silva se hallan las "Rimas de

${ }^{4}$ Emilio Cotarelo y Mori, Colección de entremeses..., I, en NBAE, t. 17, p. cxviii.

5 Véase la edición del Cancionero de la Academia de los Nocturnos de Valencia por Francisco Martí Grajales, Valencia, 1905. Cf. también su Ensayo de un dicc. biogr. y bibliogr. de los poetas ... de Valencia hasta el año 1700 , Madrid, 1927, pp. 72-75.

${ }^{6}$ Este Pedro (o Pietro) Medici fue hijo natural de cierta Antonia Caravajal y de Pietro de Medici, hijo de Cosimo I. A la muerte de su padre (en Madrid, 1604) fue enviado a Italia con otros hijos ilegítimos del forentino. Murió en 1654 a los 66 años de edad.

7 Véase Marcelino Menéndez Pelayo, Hist. de los heterodoxos esp., $2^{\mathrm{a}}$ ed., Madrid, 1928 , t. 5, p. 304 .

8 Innocencio Francisco de Silva, Diccionário bibliográphico portuguez, Lisboa, 1859 , t. 2, p. 241 . 
Estevam Rodrigues de Castro, dadas a luz por Francisco de Castro, seu filho: Dirigidas ao illustrissimo senhor Capitão Pedro Capponi, cavaleiro do hábito de S. Estevão. Em Florenssa, por Zanobio Pinhoni, mercador de livros, 1629". Además, apareció en Florencia en 1639 una Postohuma varietas de las obras de Esteváo Rodrigues, impresa por la misma casa (Amador Maffi y Lorenzo Landi) que más tarde publicó las Metamorfosis. Por eso parece fuera de duda que las Metamorfosis fueron obra de un Francisco de Castro, portugués, hijo de Estevão Rodrigues de Castro. Desgraciadamente, nada sabemos de su vida, fuera de lo que dice él mismo en la dedicatoria.

Sólo a título de curiosidad mencionaré otros dos personajes del mismo nombre que vivieron en el siglo xvn. Uno vivió de 1574 a 1653 y fue obispo de Guarda. Escribió una obra Augustissimo Hispaniarum principi recens nato Philippo Dominico Victorio Austriaco (Conimbricae, 16o6). El otro fue el segundo hijo del Conde de Lemos y lugarteniente de su padre en el reino de Nápoles de 1601 a 1603 . En 1629 ingresó en la orden benedictina con el nombre de fray Agustín de Castro y murió en 1637. Bartolomé Leonardo de Argensola le dirigió el poema "Joven leal por el poder del hado..." Ni el uno ni el otro pudieron ser autor de las Metamorfosis.

KenNeth R. SCholberg

Northwestern University.

\section{EL DUENDE DE VALLADOLID DE GARCÍA GUTIÉRREZ}

En una nota al verso "Perdónenme mis lectores", al final del romance IV de su leyenda $E l$ duende de Valladolid", Antonio García Gutiérrez hace saber que su fuente es el libro en castellano y latín del doctor Pedro Sánchez de Aguilar, Informe contra idolorum cultores del obispado de Yucatán $^{2}$. El autor de El trovador llegó a conocer el pasaje del Informe que trata del estupendo duende de Valladolid durante su primera estancia en Mérida ${ }^{3} \mathrm{y}$, necesariamente, por la intervención directa de don

${ }_{1}$ Poesias de Antonio Garcia Gutiérrez, sel. y pról. de J. de Entrambasaguas, Madrid, 1947 (Bibl. selecta de clás. españoles), pp. 357-377.

${ }^{2}$ Este volumen en $4^{\circ}$, con 8 folios prels. y 124 de texto, fue impreso por la viucla de Juan Gonçález, en Madrid, en 1639. La $2^{\text {a }}$ ed. se publicó en México en 1892 en el t. 6, pp. 13-22, de los Anales del Museo Nacional, con la parte latina traducida por don Vicente de P. Andrade. La $3^{\text {a }}$ ed., que es la que utilizamos, va precedida de una breve biografía del autor por don Francisco Cantón Rosado, y fue impresa en 1937 en Mérida (Yucatán); se sirve de la reimpresión de 1892 , de la cual toma sólo el texto en español.-Don Pedro Sánchez de Aguilar nació en Valladolid de México el 10 de abril de 1555. Obtuvo el doctorado en la Universidad de México. Fue cura en varias parroquias antes de ascender a deán de la catedral de Mérida. El Rey de España le nombró canónigo de la catedral metropolitana de la ciudad de la Plata (hoy Sucre, Bolivia). Tomó posesión de su canonjía en 1621 , y continuó en el cargo hasta su muerte en 1648. Véase: "Duende de Valladolid", en Museo Yucateco, ed. Justo Sierra O'Reilly (periódico impreso en Campeche, año 1841 ), pp. $3^{1} b-3^{2} b$; Gerónimo Castillo, Diccionario histórico, biográfico y monumental de Yucatán, Mérida, 1866, t. 1, pp. 282-284 (reproducción exacta de los comentarios de Sierra); Gustavo Martínez Alomía,

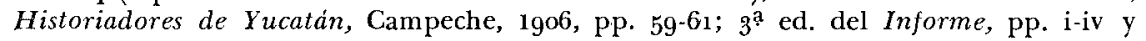
197-203.

${ }^{3}$ Salió de la Habana el 18 de marzo de 1845 y antes del $1^{\circ}$ de abril ya estaba en 